\title{
Kajian Strategi Integrasi Nilai-Nilai Keberlanjutan Kedalam Proses Pembangunan Kelapa Sawit Rakyat Di Tapanuli Selatan
}

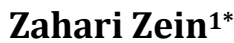 \\ Retna Astuti Kuswardani ${ }^{2}$ \\ Yusniar Lubis ${ }^{3}$ \\ 1Fakultas Ekonomi Universitas Harapan Medan \\ 2,3Pascasarjana Magister Agribisnis Universitas Medan Area \\ *email: zaharizein@gmail.com \\ Diterima: Agustus 2020; Disetujui: Februari 2021; Dipublish: April 2021
}

\begin{abstract}
Abstrak
Perkembangan luas areal kelapa sawit sangat mengkhawatirkan karena sudah merangsek ke areal dengan kemiringan lebih dari 40\%. Masalahnya bukan hanya karena nilai produktivitas sawit yang rendah, tetapi juga karena laju deforestasi semakin meningkat. Kajian bertujuan untuk mengidentifikasi nilai keberlanjutan kelapa sawit di Tapanuli Selatan, dalam rangka memberikan pilihan strategi penerapan Rencana Aksi Sawit Berkelanjutan (RAD-SB). Metode yang digunakan dalam penelitian ini adalah eksploratif dan survei lapangan dengan Interview terstruktur dan tidak terstruktur dengan petani independen, agen TBS dan pengelola PKS. Hasil penelitian dikelompokkan dua strategi yaitu strategi pada tingkat kelembagaan di Kabupaten dan strategi pada tingkat lapangan di Desa. Pada tingkat kelembagaan di Kabupaten terlihat bahwa peranan lembaga pendukung yang tergabung dalam FOKSBI masih belum solid, meskipun sudah memiliki komitmen yang sama untuk menerapkan aksi pembangunan sawit berkelanjutan.Elaborasi aspekaspek keberlanjutan yang diperlukan untuk menerapkan RAD-SB masih dimengerti dalam dimensi yang berbeda-beda. Strategi tingkat lapangan bertujuan untuk mencari cara-cara atau sistem budidaya sederhana untuk meningkatkan pendapatan petani, tanpa merusak sumberdaya hutan dan lahan. Terdapat potensi yang besar untuk meningkatkan produktivitas TBS tanpa merusak sumberdaya alam, meningkatkan kualitas buah dan melepas jerat monopoli pasar TBS yang terjadi. Praktik budidaya ekspansif dapat diubah menjadi budidaya hemat lahan dengan sistem perkebunan yang lebih intensif dan teknologi yang sederhana, murah, mudah dan memenuhi persyaratan konservasi. Penguatan lembaga penyuluhan dan pendanaan berkelanjutan merupakan keniscayaan penerapan RAD-SB agar meeningkatkan output dan outcome yang nyata, yaitu terwujudnya kesejahteraan petani secara luas dan terwujunya sustainable-landscape di Tapanuli Selatan.
\end{abstract}

Kata Kunci: Ekonomi, Ekologi, Sosial, Sawit, Berkelanjutan, Kelembagaan

\begin{abstract}
The development of the area of oil palm is very worrying because it has pushed into areas with a slope of more than $40 \%$. The problem is not only because of the low value of palm oil productivity, but also because the rate of deforestation is increasing. The study aims to identify the sustainable value of oil palm in South Tapanuli, in order to provide strategic options for implementing the Sustainable Palm Oil Action Plan (RAD-SB). The methods used in this study were exploratory and field surveys with structured and unstructured interviews with independent farmers, FFB agents and PKS managers. The results of the study are grouped into two strategies, namely the strategy at the institutional level in the district and the strategy at the field level in the village. At the institutional level in the district, it appears that the role of the supporting institutions that are members of the FOKSBI is still not solid, even though they already have the same commitment to implementing sustainable palm oil development actions. The elaboration of the sustainability aspects needed to implement RAD-SB is still understood in different dimensions- different. The field-level strategy aims to find simple cultivation methods or systems to increase farmers' income, without destroying land and forest
\end{abstract}


resources. There is great potential to increase FFB productivity without destroying natural resources, improving fruit quality and releasing the monopoly trap that occurs in the FFB market. Expansive cultivation practices can be transformed into land-efficient cultivation with a more intensive plantation system and technology that is simple, cheap, easy and meets conservation requirements. Strengthening extension agencies and sustainable funding is a necessity in implementing RAD-SB in order to increase tangible output and outcomes, namely the realization of a broader welfare of farmers and the realization of a sustainable landscape in South Tapanuli.

\section{Keywords: Economic, Ecological, Social, Palm Oil, Sustainable, Institutional}

\section{PENDAHULUAN}

Seperti juga di kabupaten-kabupaten lain di Indonesia, deforestrasi sangat pesat terjadi di Kabupaten Tapanuli Selatan. Hutan-hutan yang baik untuk ketahanan lingkungan hidup dari bencana iklim seperti longsor dan banjir. Saat ini hutan-hutan konservasi telah rusak begitu parah karena perambahan dan illegal logging. Walaupun program pemerintah dalam melindungi hutan sudah sejak lama dilakukan di Tapanuli Selatan, namun terasa masih kurang efektif dalam mencegah perambahan oleh masyarakat untuk usaha pertanian dan perkebunan. Perkembangan perluasan usaha perkebunan rakyat khususnya kelapa sawit terus merangsek ke hutan konservasi.

Dari segi pertumbuhan ekonomi, perkebunan kelapa sawit telah berperan meningkatkan pendapatan bagi masyarakat desa terutama di luar Jawa, pendapatan mereka dari kelapa sawit lebih besar daripada komodit lain. GDP di daerah yang areal perkebunannya dominan kelapa sawit lebih tinggi daripada provinsi lain Sumatera Utara dan Riau merupakan produsen utama kelapa sawit. Kelapa sawit telah berperan menurunkan angka kemiskinan di daerah yang areal kelapa sawitnya luas, sebagai contoh di Provinsi Riau dalam periode 5 tahun (2009-2013) pembangunan kelapa sawit telah menurunkan angka kemiskinan dari 21\% menjadi 10\% (Sipayung 2014).

Namun sayangnya dari segi lingkungan hidup beberapa peneliti mencatat pembangunan kelapa sawit juga meningkatkan laju kerusakan hutan dan lahan gambut akaibat pembangunan sawit yang tidak berkelanjutan (Obidzinski, K. Andriani, R., Komarudin, H., and Andrianto, 2012; Mangga Barani, A. 2014. Kesimbangan antara kepentingan ekonomi dan lingkungan dan arah pembangunan berkelanjutan dibahas lebih seimbang oleh McCarthy and Zen (2010).

Keseimbangan antara ekonomi dana lam itulah tujuan perlunya kegiatan konservasi alam dan sekaligus meningkatkan kesejahteraan masyrakat. Conservation International (CI) adalah lembaga non profit yang berpusat di Amerika Serikat, di Indonesia dikenal dengan CI Indonesia. Dalam 30 tahun terakhir CI telah berperan melindungi bumi dan mendorong, membantu dan bekerjasama dengan negara-negara berkembang dengan ilmu pengetahuan mutakhir, kebijakan yang inovatif. CI memberdayakan masyarakat untuk melindungi alam dimana kita tergantung pada kebutuhan pangan, air dan mata pencaharian penduduk (https://www.conservation.org/) 
Sejak 2013 CI Indonesia telah berkontribusi membantu pemerintah dengan program Sustainable Landscapes Partnership (SLP) di tiga Kabupaten di Sumatera Utara yaitu Kabupaten Tapanuli Selatan, Tapanuli Utara dan Kabupaten Mandailing Natal. SLP melakukan kemitraan dengan pemerintah kabupaten mitra dengan organisasi non-pemerintah untuk mengatasi secara bersama-sama masalah budidaya ekspansif, perkebunan sawit, karet, kopi dan kakao; dan usaha dalam rangka mitigasi dan adaptasi terhadap perubahan iklim dan usaha-usaha konservasi hutan. CI dengan program SLP mendukung pemerintah daerah dalam aspek tehnis dan pembiayaan dengan konsep smart land uses planning, meningkatkan kemampuan manajemen hutan, penyuluhan pertanian berkelanjutan dan usaha-usaha memperbaiki sistem rantai pasok komoditi sawit, karet dan kakao. Pendekatan pembangunan bentang alam adalah sebuah kerangka untuk proses pengambilan keputusan konservasi skala luas yang terkait dengan aktivitasaktivitas seperti pembangunan jalan baru atau perkebunan (CI- Indoesia, 2005)

CI Indonesia telah dan akan bekerja dengan pemerintah Tapanuli Selatan untuk mengembangkan perkebunan berkelanjutan, dan juga bekerjasama dengan perusahaan perkebunan dan sektor swasta lainnya. Lokal LSM, akademisi dan masyarakat yang sangat diperlukan dalam pelaksanaan RAD SB. Penelitian ini merupakan kajian awal dalam mengembangkan Rencana Aksi Sawit Berkelanjutan Kabupaten Tapanuli
Selatan. Mendukung pemerintah Kabupaten Tapanuli Selatan dalam mewujudkan produksi minyak sawit berkelanjutan berdasarkan Hukum Indonesia dan memastikan perlindungan ekosistem dan hutan lindung sebagai bagian dari sistem penyangga kehidupan yang bermanfaat khususnya bagi masvarakat Tapanuli Selatan.

Hutan Tapanuli Selatan telah diakui secara global penting sebagai habitat untuk bagi sejumlah spesies fauna dan flora yang sekarang sedang terancam eksistensinya. Hutan di Tapanuli Selatan tidak saja penting secara nasional bahkan ekosistem global. Dalam beberapa dekade terakhir, ekosistem dan spesies di dalamnya berada di bawah ancaman karena meningkatnya konversi hutan menjadi lahan usaha pertanian dan perkebunan rakyat (Zen et all, 2018).

Kajian ini dilakukan dalam rangka memberikan rekomendasi pembangunan kelapa saawit berkelanjutan di Tapanuli Selatan, Cl Indonesia memberikan bantuan pendanaan untuk melakukan kajian ini. Hasil kajian ini digunakan sebagai bahan diskusi dan komunikasi dengan para pihak di daerah dalam upaya memberikan rekomendasi untuk pengelolahan bentang alam yang lebih baik dan berkelanjutan di Kabupaten Tapanuli Selatan dengan tetap menjamin kesejahteraan masyarakat.

Kajian ini bertujuan untuk mengidentifikasi nilai keberlanjutan seperti nilai-nilai ekonomi, nilai-nilai ekologi dan nilai-nilai sosial dalam mendukung budidaya kelapa sawit berkelanjutan. Hasil penelitian ini diharapkan memberikan pilihan strategi 
sebagai bagian dalam penerapan pengelolaan Rencana Aksi Sawit Berkelanjutan (RAD-SB) yang lebih baik dari yang sebelumnya yang telah dilakukan. Sebagaimana yang digariskan pemerintah daerah bahwa tujuan RADSB adalah untuk mendorong pengelolaan sumberdaya alam yang lebih berkelanjutan sehingga terwujud sustainable landscape di Tapanuli Selatan yaitu hutan terjaga dan perkebunan yang lebih produktif.

\section{METODE PENELITIAN}

Untuk mencapai tujuan tersebut, dilakukan penelitian pada bulan Agustus 2020 hingga Desember 2020 dengan metode eksploratif terhadap isu keberlanjutan dengan melakukan survei di daerah yang akan dikembangkan pemerintah daerah. Untuk menunjang survey lapangan, dengan bantuan CI Indonesia, peneliti mengadakan FGD dengan unsur yang tergabung dalam FOKSBI. Interview juga dilakukan dengan staf Dinas Tanaman Pangan dan Perkebunan Tapsel, KPH (Kesatuan Pengelolaan Hutan) Tapsel, Dinas Lingkungan Hidup, staf $\mathrm{CI}$, Penyuluh pertanian dan Perkebunan dan Petani sawit independen dari seluruh Kabupaten Tapanuli Selatan.

Metode analisis dilakukan dengan membuat model pengelolaan sawit berkelanjutan yang yang akan diuji dari berbagai aspek yang berkaitan dengan aspek-aspek ekonomi, aspek ekologi dan sosial dan aspek kelembagaan yang bisa mendorong terjadinya proses pembangunan Kelapa Sawit berkelanjutan. Kemudian hasil-hasil analisis sementara diuji kesesuaiannya dengan kondisi di lapangan. Peneliti menguji antara lain pelaksanaan prinsipprinsip teknis agronomis dalam budidaya sawit, prinsip-prinsip konservasi ekologis dan analisis ekonomi terhadap praktek budidaya sawit yang diterapkan petani selama ini. Untuk memperkuat rekomendasi peneliti melakukan kajian investasi komoditi kelapa sawit dan membandingkannya dengan komoditi-komoditi unggulan lainnya.

\section{HASIL DAN PEMBAHASAN}

\section{Strategi Pembangunan Sawit Pada Tingkat Kabupaten}

Pada tingkat kelembagaan seperti di tingkat Kabupaten Tapanuli Selatan bahwa aspek-aspek nilai ekonomi, nilai ekologi maupun nilai sosial dalam proses pembangunan di Tapanuli Selatan belum terintegrasi dengan baik (lingkaran sebelah kiri Gambar 1. walaupun kegiatan-kegiatan pembangunan sawit berkelanjutan sudah dilaksanakan secara parsial. Gambar 1 sisi kiri adalah lingkaran-lingkaran aspek keberlanjutan yaitu aspek ekonomi, ekologi dan sosial pada kondisi saat ini. Dimana kemitraan terpadu belum terbentuk dengan baik. Sebelah kanan adalah lingkaranlingkaran yang diinginkan. Sedangkan dibagian tengah diagram adalah peranan CI sebagai driving force untuk memperkuat kapasitas kelembagaan untuk mendorong terjadinya proses integrasi. Laporan lengkap terdapat pada laporan akhir hasil studi kajian ekonomi, ekologi dan sosial kelapa sawit di TAPANULI SELATAN (Zen dan Shahputra, 2019).

Peran kelembagaan yang ada di tapanuli Selatan yang terkait dengan konservasi Sumber Daya Alam (SDA) 
belum memadai, karena belum fokus kepada sawit berkelanjutan, pemahaman terhadap perlunya kerjasama antar instansi untuk mengatasi masalah petani sawit independen yang ekspansif masing sangat terbatas, karena petani belum memahami sistem budidaya sawit yang lebih maju dan konservatif. Instansiinstansi yang ada hanya melihat persoalan sawit dari persepsi masingmasing.

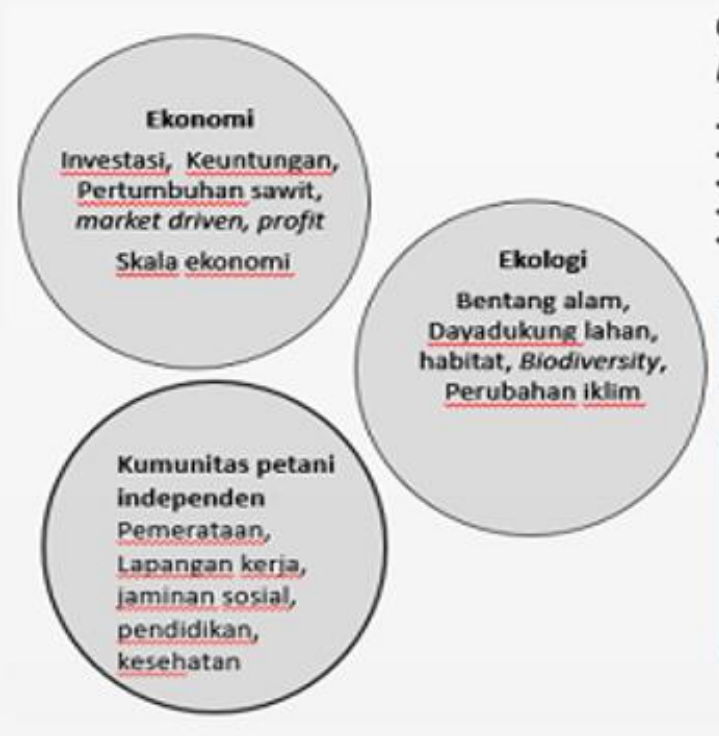

Belum ada upaya penyatuan ide secara terpadu untuk menunjang agar tercipta kegiatan sawit berkelanjutan dan meluas di seluruh Kabupaten Tapanuli Selatan. Oleh sebab itu memperkuat ikatan kelembagaan dalam forum FOKSBI adalah kunci suksesnya RAD-SB. Keterbatasan pendanaan untuk RAD-SB dapat diatasi bila sinergi anggaran dapat

Gambar 1 Proses integrasi nilai sawit berkelanjutan

dilakukan misalnya penyediaan dana dari Dinas pertanian dan Perkebunan ditunjang dari pendanaan KPH, Dinas Lingkungan Hidup. Sehingga program RAD-SB dengan kegiatan yang lebih luas bisa dilaksanakan.

Kemampuan lembaga didaerah yang terkait dengan pemberdayaan masyarakat seperti Dinas tanaman Pangan dan Perkebunan (Distanbun), Kesatuan Pengelolaan Hutan (KPH), perusahaan Negara dan Swasta masih terbatas, terutama dalam pendanaan kegiatan lapangan, masih secara parsial sehingga outcome nya belum terlihat, karena perambahan masih terjadi di Tapanuli Selatan.

Mengingat luasnya areal sawit yang perlu ditingkatkan produktivitasnya ditambah dengan kondisi kemiskinan di pedesaan, maka tidak memungkinkan petani melakukan intensifikasi tanpa bantuan. Bantuan pengadaan sarana produksi seperti bibit unggul sawit, pupuk, obat-obatan dan peralatan bisa dilakukan misalnya dengan memberi subsidi harga. Dengan perkataan lain, pada saat studi ini dilakukan petani independen belum tersentuh teknologi budidaya sawit yang lebih produktif dan konservatif. 
Peranan pemerintah daerah dalam mengarusutamakan (RAD-SB) ke dalam RPJMD yang dimulai dari tahapan perencanan bersama, FOKSBI sebagai forum menyatukan ide-ide keberlanjutan menjadi sangat penting dalam membantu proses integrasi keberlaniutan ke dalam arus utama pembangunan. Untuk itu

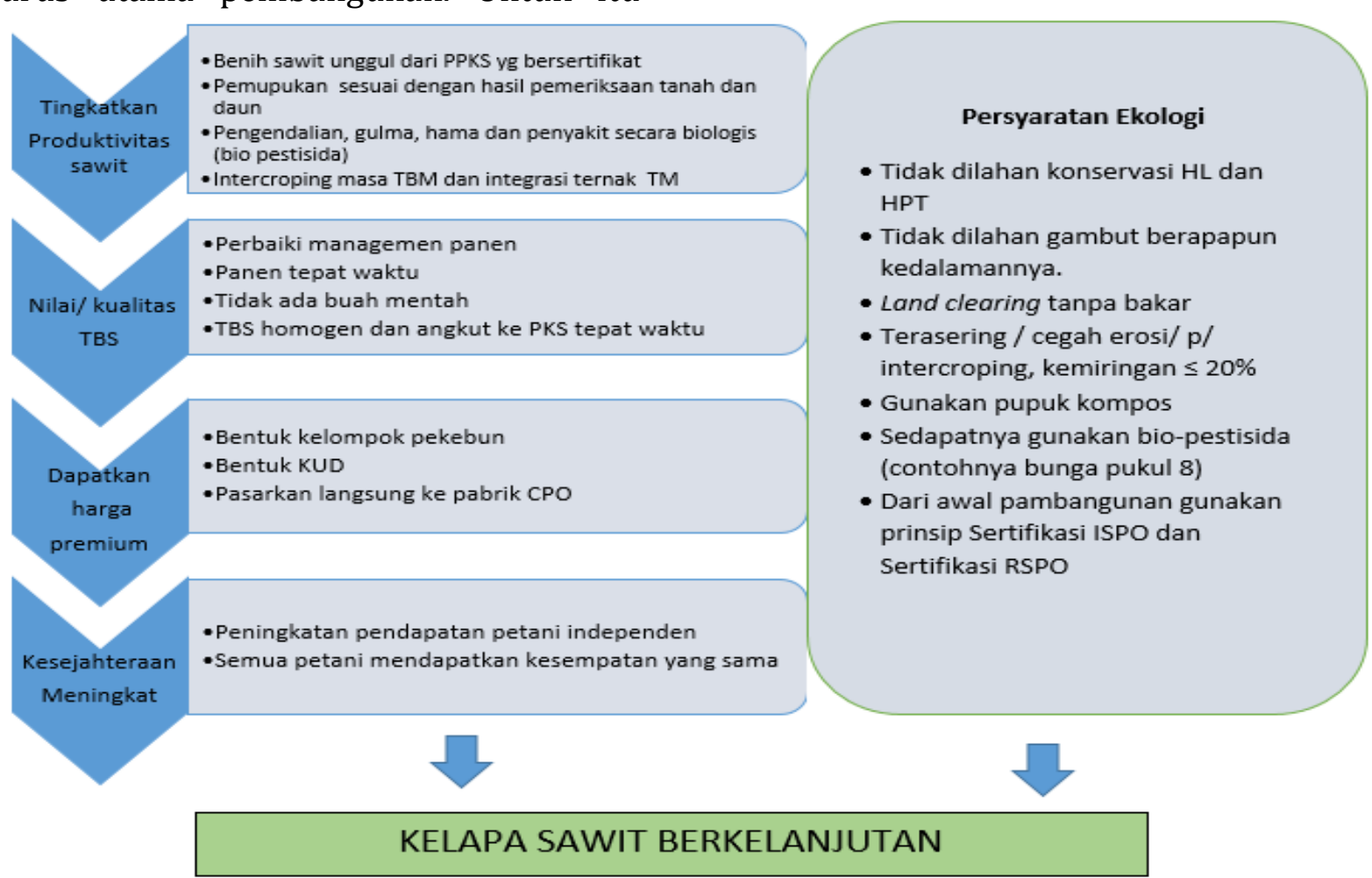

Gambar 2. Konsep meningkatkan pendapatan petani sawit independen secara berkelanjutan

untuk menajamkan tujuan dan target yang ingin dan telah dicapai dari proyek ini dan untuk mendapatkan komitmen stakeholders dalam rangka mengarusutamakan program RAD-SB ke dalam RPJMD dan RKPD.

\section{Strategi Pembangunan Sawit Pada Tingkat Lapangan}

Secara teknis, kunci meningkatkan kesejahteraan petani independen dimulai dari upaya dalam meningkatkan produksi per hektar (produktivitas), meningkatkan kualitas TBS dan pada saat ini pemerintah perlu membuat kelompok kerja (Task Force $=\mathrm{TF}$ ) untuk menyusun RAD-SB yang anggotanya berasal dari unsur FOKSBI didukung oleh beberapa orang tenaga ahli. TF mengadakan workshop hasil pekerjaannya dengan FOKSBI
- Tidak dilahan konservasi HL dan HPT

Tidak dilahan gambut berapapun kedalamannya.

Land clearing tanpa baka - Terasering / cegah erosi/ $\mathrm{p} /$ intercroping, kemiringan $\leq 20 \%$

Gunakan pupuk kompos

- Sedapatnya gunakan bio-pestisida prinsip Sertifikasi ISPO dan Sertifikasi RSPO memperbaiki rantai pasok, sehingga petani independen menerima harga TBS premium sesuai ketetapan "Permentan No. 395/2005 Tentang Pedoman penetapan harga pembelian tandan buah segar (TBS) kelapa sawit" produksi petani Independen. Permentan tersebut setiap dua minggu diumumkan ditingkat Provinsi Sumatera Utara. Program tersebut harus berialan secara serentak dan telah direncanakan sejak awal. Persyaratan agronomis dan persyaratan 
ekologi yang dimaksud adalah seperti digambarkan pada Gambar1.

Dari pengamatan, tingkat produktivitas petani independen di Tapanuli Selatan sangat rendah. Banyaknya "benih palsu" atau benih yang tidak tersertifikasi dijual di daerah dengan harga yang sangat murah. Harga benih tidak tersertifikasi (sertifikasi palsu) hanya sekitar Rp 250.000/ kampil, 1 kampil 1000 benih atau hanya Rp 250 /benih. Bandingkan dengan harga benih unggul Rp7500/ benih dan harga bibit unggul mencapai Rp35.000Rp40.000/bibit, belum termasuk ongkos angkut. Dengan penghasilan yang rendah (Tabel 1) perlu memberi harga subsidi dan pendanaan investasi awal agar dapat dapat menjadi peserta. Beberapa petani yang sudah mulai sadar akan pentingnya bibit unggul bersertifikat sudah ada, misalnya di Desa Pardomuan mereka berkelompok dan di organisir oleh Penyuluh pertanian untuk mendapatkan surat rekomendasi dari Dinas Pertanian untuk membeli benih sawit unggul bersubsidi dari PPKS dengan harga yang sangat rendah hanya RP5500/benih, bandingkan harga tanpa subsidi di PPKS Rp7500/benih, harga di PT Socfin Rp $14000 /$ benih unggul. Sehingga untuk skala kabupaten, petani independen memerlukan bantuan subsidi benih yang sangat banyak mengingat luasnya areal sawit rakyat.

Kegiatan pembelian benih unggul telah dikoordinir oleh penyuluh, tahun ini (2018) ada 12 orang petani memesan 1000 benih unggul bersertifikat di
Kecamatan Kecamatan Pardomuan. Periode sebelumnya satu orang petani independen membeli 5000 benih unggul dan membuat pembibitan sendiri untuk keperluan kebun sendiri dan dijual sebagian kepada petani independen lain. Hasil interview beberapa petani pada tanaman sawit yang berusia optimal (berkisar umur tanaman 10-18 tahun) produktivitas sawit hanya sekitar 16,8 ton TBS/ha/th untuk petani tradisional dan 28,8 ton/ha/th ton TBS/tahun untuk petani semi intensif, diperkirakan potensi produktivitas sawit rakyat bisa mencapai 30 ton TBS/ha tahun bila persyaratan agronomis dipenuhi. Kondisi tersebut menghasilkan produktivitas TBS yang sangat rendah dengan kualitas TBS yang sangat buruk.

Bagaimanapun buruknya kondisi kebun dan rendahnya harga sawit mereka masih memanen sawit. Petani tidak akan menumbang pohon tersebut karena menerima penghasilan dari kebun ini setiap 2 minggu. Pohon sawit diibaratkan sebagai ATM walau sedikit mereka mendapat uang. Petani sawit bisa disebut "petani malas" karena untuk panen saja (mendodos) mereka menggunakan buruh panen (dodos). Upah dodos dan lansir ke tempat penimbangan sekitar Rp 150/kg TBS/per panen hingga Rp300/kg TBS/ panen tergantung tingkat kesulitan panen, pada daerah yang kemiringan ekstrem (curam) biaya panen Rp 300/kg TBS. Ilustrasi keadaan penerimaan petani independen disajikan pada Tabel 1. 
Tabel 1. Estimasi pendapatan petani sawit per hektar pada usia tanaman sawit 10-18 tahun

\begin{tabular}{|c|c|c|c|c|c|}
\hline No. & $\begin{array}{l}\text { Kelompok Petani } \\
\text { Independen }\end{array}$ & $\begin{array}{l}\text { Produksi } \\
\text { TBS } \\
\text { (ton } \\
\text { TBS/bulan*) }\end{array}$ & $\begin{array}{l}\text { Penerimaan } \\
\text { Kotor } \\
\text { Per } \\
\text { bulan/ha** } \\
\text { (dalam juta } \\
\text { Rp) }\end{array}$ & $\begin{array}{l}\text { Penerimaan } \\
\text { bersih } \\
\text { perbulan** } \\
\text { (dalam juta } \\
\text { Rp) }\end{array}$ & $\begin{array}{l}\text { Pendapatan } \\
\text { Per } \\
\text { 2ha/petani/bulan }\end{array}$ \\
\hline & Petani Semi Intensif & 2,5 & 2,9 & 2,7 & 5,2 \\
\hline & Petani Tradisional & 1,6 & 1.2 & 0,7 & 1,9 \\
\hline & Gap Petani (1) dan (2) & 0.9 & 1,7 & 1,4 & 2,8 \\
\hline
\end{tabular}

Sumber: Survey lapangan 12-14 September 2018

Catatan:

*) Data survey lapangan pada tanggal 12-14 September 2018, rata-rata umur tanaman sawit 10-16 tahun (usia puncak produktivitas sawit) dan panen dua kali dalam satu bulan.

**) Harga TBS petani semi intensif dengan kelompok tani Rp 1180/kg (harga di pintu pabrik PT.ANJ atau factory gate price); Harga TBS petani tradisional (di pintu petani atau farm gate price) yang diterima dari Agen Desa Rp 870/kg

**) Setelah dikurangi dengan upah dodos dan langsir kepinggir jalan (Rp 300/ kg/bl) (sumber: Desa Terapung Raya)

Dari Tabel 1. terlihat gap atau celah produktivitas yang cukup lebar antara petani tradisional dengan petani semi intensif. Hal ini dapat diduga karena belum efektifnya kegiatan penyuluhan sehingga kegiatan yang mendorong petani melakukan intensifikasi boleh dikata sangat sedikit. Demplot adalah satu cara untuk meyakinkan petani bahwa dengan lahan yang sama akan menghasilkan produksi yang lebih tinggi.

Dari interview dengan beberapa petani sawit terkesan bahwa mereka jarang atau hampir tidak pernah bertemu dengan penyuluh. Demikian pula penyuluh yang diwawancarai menjelaskan bahwa covare area mereka terlalu luas, mereka tidak hanya menyuluh tanaman sawit, tetapi juga tanaman perkebunan lainnya (penyuluh polivalen). Hal ini mengindikasikan kurangnya frekuensi kunjungan penyuluh perkebunan kepada petani sawit independen.
Pada saat ini CI memberikan pelatihan budidaya sawit berkelanjutan ditingkat TOT, yang nantinya akan melatih kelompok-kelompok tani. Namun mengingat jumlah tenaga penyuluh sangat terbatas, maka program sawit berkelanjutan sulit terlaksana secara luas dan efektif, mengingat luasnya areal sawit tradisional di Tapanuli Selatan. Jumlah dan kualifikasi penyuluh sawit adalah salah satu kunci suksesnya pengembangan sawit berkelanjutan.

Pada kunjungan ke Desa Pardomuan, ada 2 orang penyuluh polivalen yang menangani masing-masing $250 \mathrm{KK}$ petani sawit independen. Hampir semua warga desa ini memiliki sawit, maka penyuluh spesialisasi sawit sangatlah penting. Menyedihkan karena didesa ini hanya sekitar $25 \%$ saja yang menanam sawit unggul (bibit sawit yang bersertifikat), sisanya $75 \%$ adalah sawit dari bibit yang tidak tersertifikat (istilah lokal benih "mariles"). Umumnya sawit 
unggul yang ditemukan dilapangan masih relatif berumur muda, berkisar umur antara 1-10 tahun artinya petani baru mulai mengenal sawit unggul sekitar 10 tahun belakangan.

Dari 70 orang PPL di Tapsel, CI- telah melakukan TOT kepada Penyuluh sebanyak 8 orang dan kader desa sebanyak 14 orang. Mengingat terbatasnya penyuluh dari Dinas Tanbun, maka pelatihan berikutnya perlu memperbanyak peserta petani kader. Tentu saja kader desa yang memiliki legalitas lahan, atau areal yang tidak berada dikawasan hutan konservasi. Kader-kader ini bisa juga menjadi mitra dalam Demplot didesa dikemudian hari. Pada umumnya petani independen memiliki lahan lebih dari 2 ha agar mampu mencukupi ekonomi rumah tangga. Karena sangat tergantung pada lahan yang relatif sempit, maka untuk program mengganti tanaman yang tidak produktif bisa dilakukan secara bertahap, misalnya peremajaan $1 \mathrm{ha}$ / th, tanpa mengurangi pendapatannya secara signifikan diikuti dengan bimbingan menanam tanaman sela.

Fenomena di Tapanuli Selatan, pembukaan lahan baru tidak saja bertujuan untuk penanaman tanaman sawit atau tanaman perkebunan lainnya, tetapi juga untuk menunjang kebutuhan pangan dan sedikit dana untuk kebutuhan RT lainnya. Dari observasi dilapangan, para petani independen setelah membuka lahan segera menanam tanaman sela diantara barisan sawit (intercroping), bahkan mereka menanam lebih dahulu tanaman pangan sebelum menanam sawit.

Komoditi yang paling banyak diusahakan petani adalah padi ladang, jagung dan pisang. Estimasi pendapatan dari dari 3 jenis tanaman sela disajikan pada Tabel 2. Asumsi perhitungan:

Tahun - 0 : Petani Tradisional : Padi gogo padi tahun ke 0 menghasilkan 4 ton gabah kering panen pertahun dengan harga Rp5000/kg, pendapatan padi sekitar Rp20jt; pada musim kemarau ditanam jagung; Hasil jagung 6 ton/ha/th

Tabel 2. Pendapatan Petani Independen dari Tanaman Sela di Tapanuli Selatan

\begin{tabular}{ccccc}
\hline $\begin{array}{c}\text { Tahun Tanam } \\
\text { Sawit }\end{array}$ & $\begin{array}{c}\text { Pendapatan Kotor } \\
\text { Petani } \\
\text { Tradisional } \\
\text { (j)/th) }\end{array}$ & $\begin{array}{c}\text { Semi Intensif }{ }^{\text {) }} \\
\text { (Rp jt/th) }\end{array}$ & $\begin{array}{c}\text { Pendapatan Bersih } \\
\text { Tradisional } \\
\text { (Retani } \\
\text { jt/th) }\end{array}$ & $\begin{array}{c}\text { Petani semi } \\
\text { intensif*) (Rp } \\
\text { jt/th) }\end{array}$ \\
\hline 0 & 35,0 & 42,5 & 24,5 & 29,75 \\
1 & 38,5 & 46,8 & 26,95 & 32,76 \\
2 & 22,4 & 24,6 & 15,68 & 17,22 \\
3 & 4,5 & 5,4 & 3,15 & 3,78 \\
\hline
\end{tabular}

Sumber: Survey lapangan 12-14 September 2018

Catatan :

${ }^{*}$ Tahun-0 ditanam padi dan jagung; Tahun-1 ditanam padi dan jagung; Tahun-2 ditanam jagung dan pisang, padi tidak ditanam; Tahun-3 hanya panen tanaman pisang, , biaya produksi $30 \%$ dari nilai produksi tidak diperhitungkan biaya.

dengan harga Rp2500 atau pendapatan Rp15 juta;Total Pendapatan 35 juta/ha/th. Petani semi intensif : Produksi padi 5 ton dengan harga 
Rp5000/kg gabah kering panen 25 juta; produksi jagung 7 ton pipilan dengan harga Rp2500/kg pendapatan dari jagung 17.500 .000 total pendapatan Rp42,5 juta/tahun.

Tahun - 1 : Petani Tradisional dan petani semi intensif untuk produksi padi dan jagung ditaksir naik sekitar 10\% karena kondisi penanaman lebih baik, bekas kayu-kayu bekas tebangan yang mengambil ruang telah disingkirkan. Sehingga pendapatan kotor petani tradisional Rp38,5jt dan pendapatan kotor petani semi intensif $\mathrm{Rp} 46,8 \mathrm{jt}$ ha/th

Tahun - 2 : Petani Tradisional : Pada tahun 2 padi tidak ditanam hanya jagung dengan produksi 6 ton/ha/th dengan harga Rp2500/kg maka pendapatan dari jagung Rp15juta/tahun. Produksi pisang 600 tandan per tahun per ha, harga pertandan Rp14.000, total pendapatan pisang pertahun Rp8,4juta/ha/tahun. Total pendapatan dari jagung dan pisang Rp22,4 juta/tahun. Untuk petani semi intensif produksi kira-kira lebih tinggi $10 \%$ dari pada petani tradisional, sehingga pendapatan total ditaksir sekitar 24,6 juta/ha/tahun (Sumber: Wawancara petani di Desa Janji Martogu)

Tahun - 3 : Petani Tradisional untuk tahun 3 hanya panen pisang dan produksi menurun karena areal panen semakin berkurang hingga 50\%. Ditaksir produksi pisang hanya 300 tandan pertahun. Sedangkan petani semi intensif sekitar 350 tandan. Dengan harga 14000 per tandan maka pendapatan petani tradisional sekitar 4,2 juta, pendapatan petani semi intensif Rp4,9 juta/ha/th.
Meskipun perlakukan hampir sama, ada beberapa alasan yang diperkirakan penyebab menurunnya produksi tanaman sela (intercropping) pada tahun kedua dan ketiga antara lain, karena kanopi sawit semakin lebar, sehingga rongga untuk tanaman sela semakin sempit. Alasan lain juga karena menurunnya kesuburan tanah, karena petani tradisional tidak melakukan pemupukan. Semakin meningkat umur TBM maka persaingan unsur hara semakin meningkat dan terjadi penurunan tingkat kesuburan tanah. Terlihat dari Tabel diatas bahwa produksi petani semi intensif lebih tinggi daripada petani tradisional. Hal ini karena ada pengaruh pemupukan sawit yang berdampak kepada tanaman sela, sementara petani tradisional tidak melakukan pemupukan. Sebagian dari lahan petani berada dikawasan konservasi dan ada pula meskipun bukan dihutan konservasi tetapi dikawasan lindung dan hutan produksi terbatas.

Beberapa petani pendatang ada yang sudah melakukan intensifikasi, akan tetapi kebanyakan cenderung berkebun secara ekspansif. Menurut Angelson (2010) bila intensifikasi dilakukan ada dua kemungkinan, pertama dengan intensifikasi bisa meningkatkan laju deforestrasi, karena nilai rente tanah akan meningkat yang mendorong petani independen membuka lahan hutan baru dan atau melakukan konversi lahan lain untuk tanaman sawit; kemungkinan kedua bisa juga menurunkan laju deforestrasi karena mereka fokus untuk memelihara kebun dengan baik atau bila petani takut risiko pelanggaran hukum akan terjadi bila pembukaan hutan 
dilakukan dikawasan konservasi, karena peraturan-peraturan yang membatasi akses ke kawasan hutan konservasi. Itulah sebabnya kesuksesan program RAD-SB sangat ditentukan oleh capaian outcome yang disebabkan kesadaran petani meningkat. Dengan perkataan lain, peraturan Rencana Tata Ruang Kabupaten (RTRWK) betul-betul bisa ditegakkan.

Rencana Tata Ruang Wilayah Kabupaten (RTRWK) harus didasari dari hasil kajian lingkungan hidup strategis (KLHS) yang benar, batas lahan konservasi harus dikenali oleh semua masyarakat tani. Program yang paling ideal untuk melindungi hutan tersebut bilamana masyarakat dengan kelembagaannya berperan aktif dalam melindungi hutan. Pembangunan sosial yang dimaksudkan disini adalah bahwa pembinaan petani untuk menjadi petani maju memberikan efek konservatif.

Tabel 3. Biaya Investasi Sawit di Tapanuli Selatan

\begin{tabular}{lllll}
\hline No. & Item Investasi & Semi Intensif & Tradisional & Margin \\
\hline 1 & Harga dipintu pabrik & $1.180^{\text {a) }}$ & $870^{\mathrm{b})}$ & 310 \\
2 & Produktivitas (kg TBS/ha) & 19.801 & 11.881 & 7920 \\
3 & $\begin{array}{l}\text { Tingkat bunga bank } \\
\text { (asumsi) }\end{array}$ & $12 \%$ & $12 \%$ & 0 \\
4 & Tingkat Upah (Rp/hari)c) & 150.000 & 150.000 & 0 \\
5 & Biaya panen (Rp/kg TBS) d) & 150 & 150 & 0 \\
6 & Overheads (RP/kg & - & - & - \\
& TBS)(tidak dihitung untuk & & & \\
7 & petani independen) & & - & - \\
7 & $\begin{array}{l}\text { Lahan (tidak dihitung } \\
\text { sangat tergantung lokasi) }\end{array}$ & - & 359 & 89 \\
8 & Biaya Total (Rp/kg TBS) & 448 & 791 & 389 \\
9 & Penghasilan bersih (Rp/kg & 1.180 & & 136.295 .720 \\
& TBS) & & 71.701 .125 &
\end{tabular}

Sumber: Survey lapangan 12-14 September 2018

Keterangan :

a) Harga dipintu pabrik ANJ untuk petani berkelompok

b) Harga ditingkat Agen Desa Kecil

c) Tenaga keluarga tidak dihitung, yang dihitung hanya biaya tenaga kerja luar keluarga

d) Termasuk biaya lansir (angkat TBS) ke jalan penimbangan TBS

e) Investasi termasuk biaya land clearing, biaya pemeliharaan (pupuk, penyiangan piringan dan bahan herbisida dan insektisida dan biaya tenaga kerja.

Petani harus bisa merasakan manfaat dari keberadaan kawasan konservasi hutan, misalnya kesadaran akan pentingnya hutan dlm menjaga ketersediaan air untuk berbagai keperluan. Dengan intensifikasi

Kemunculan pabrik CPO terutama yang tidak memiliki kebun sangat perkebunan, diharapkan laju-laju deforestrasi di Tapanuli Selatan secara gradual akan menurun hingga ke titik nol.

Studi Kelayakan Intensifikasi Tanaman Sawit Rakyat

mendorong petani independen menanam kelapa sawit, sehingga mereka tidak 
tergantung pada pabrik PKS milik seperti PTPN 3 Hapesong dan PT ANJ dan pemerintah (PTN) atau Pabrik swasta yang perusahaan-perusahaan lain juga membeli punya lahan perkebunan. Walaupun TBS dari petani independen melalui agen dilapangan pabrik milik pemerintah sawit desa(AD).

Tabel 4. Analisis Investasi Kelapa Sawit di Tapanuli Selatan

\begin{tabular}{|c|c|c|c|c|}
\hline \multirow[b]{2}{*}{$\begin{array}{l}\text { Parameter } \\
\text { Investasi }\end{array}$} & \multicolumn{2}{|c|}{$\begin{array}{l}\text { Harga pada saat survei (harga } \\
\text { terendah) }\end{array}$} & \multicolumn{2}{|c|}{$\begin{array}{c}\text { Harga rata-rata terbaik dalam } 2 \\
\text { tahun terakhir }\end{array}$} \\
\hline & $\begin{array}{c}\text { Petani } \\
\text { Independen } \\
\text { Traditional }\end{array}$ & $\begin{array}{c}\text { Petani Semi } \\
\text { Intensif }\end{array}$ & $\begin{array}{c}\text { Petani } \\
\text { Independen } \\
\text { Traditional }\end{array}$ & $\begin{array}{l}\text { Petani Semi } \\
\text { Intensif }\end{array}$ \\
\hline B/C Rasio & 2,1 & 2,2 & 3,1 & 2,4 \\
\hline NPV (Rp) & 3.687 .399 & 13.512 .217 & 26.215 .233 & 41.046 .236 \\
\hline IRR (\%) & 13,4 & 15,1 & 20 & 20 \\
\hline PBP (th) & 10 & 10 & 9 & 10 \\
\hline
\end{tabular}

Sumber: Survey lapangan 12-14 September 2018

Untuk itu melihat kelayakan investasi disajikan pada Table 3 dan Tabel 4. Tabel 4 menunjukkan bahwa dengan kondisi harga yang rendah terutama dengan harga rata-rata terbaik, maka investasi sawit tetap menguntungkan baik dengan pertanian tradisional maupun secara semi intensif. Semua parameter investasi menunjukkan indikasi layak. Bedanya hanya pada pendapatan bersih yang jauh lebih tingi pada petani semi intensif.Tabel 4 menunjukkan bahwa dengan kondisi harga yang rendah terutama dengan harga rata-rata terbaik, maka investasi sawit tetap menguntungkan baik dengan pertanian tradisional maupun secara semi intensif. Semua parameter investasi menunjukkan indikasi layak. Bedanya hanya pada pendapatan bersih yang jauh lebih tingi pada petani semi intensif.

Pilihan Model Pengembangan Petani Sawit Independen

Pada dasarnya petani binaan SLP dapat diorganisir dalam group, agar implementasi program SLP-SB bisa terimplementasikan dengan efektif.
Namun masalah lapangan yang dihadapi adalah tersebarnya petani independen, sehingga sistem pembangunan mengelompok (block schemes) seperti pola PIR sulit dilakukan dalam skala areal yang luas, untuk itu skema yang diusulkan adalah dispersal strategy. $A$ 'dispersal strategy' is a model for plantation development for people who are not clustered in one-blok plantations and do not have a nucleus as in the PIR scheme. Dispersal strategy programs aim to increase the productivity of scattered oil palm smallholdings (Zen et. al., 2015).

Komparasi Sawit dengan Komoditi Perkebunan Lain

Untuk menjelaskan rasionalitas pilihan petani terhadap sawit dan fenomena begitu cepatnya perkembangan areal sawit independen terutama dalam 20 tahun terakhir disajikan pada Tabel 5.. Pada Tabel 5 dibandingkan tiga komoditi unggulan di Tapanuli Selatan, yaitu karet, kopi dan kakao. Variabel pembanding adalah pendapatan kotor petani, tingkat kesulitan pengelolaan, preferensi petani terhadap komoditi (data hasil dari 
interview) dan pilihan konservasi menurut penilaian penulis.

Dari Tabel 5 mendukung fakta bahwa walaupun tingkat pendapatan dari kopi dan kakao lebih tinggi daripada sawit, tetapi sawit lebih disukai karena aktivitas pemeliharaan lebih mudah, dan serangan hama dan penyakit lebih sedikit. Namun dari segi konservasi lebih baik tanaman karet menurut peneliti maupun dari publikasi-publikasi ilmiah lainnya.

Tabel 5. Perbandingan Pilihan Komoditi Perkebunan di Tapanuli Selatan

\begin{tabular}{|c|c|c|c|c|c|}
\hline No. & $\begin{array}{c}\text { Jenis } \\
\text { Komoditi }\end{array}$ & $\begin{array}{c}\text { Pendapatan } \\
\text { Kotor 1)(Jt } \\
\text { Rp/ha/bl) }\end{array}$ & $\begin{array}{c}\text { Tingkat } \\
\text { Kesulitan } \\
\text { Pengelolaan } \\
\text { Relatif } 2 \text { ) }\end{array}$ & $\begin{array}{l}\text { Preferensi } \\
\text { Petani }^{33}\end{array}$ & $\begin{array}{c}\text { Pilihan } \\
\text { Konservasi } \\
\text { 4) }\end{array}$ \\
\hline 1 & $\begin{array}{l}\text { Kelapa } \\
\text { Sawit }\end{array}$ & 2,9 & $*$ & 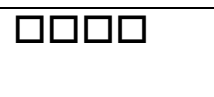 & 0 \\
\hline 2 & Karet & $0,53^{a}$ & $* *$ & ㅁㅁ & 000 \\
\hline 3 & Kopi & $\left.4,3^{b}\right)$ & *** & $\square \square$ & 000 \\
\hline 4 & Kakao & $3,5^{c}$ & $* * * *$ & $\square$ & 00 \\
\hline
\end{tabular}

Sumber: Survey lapangan 12-14 September 2018

\section{Keterangan :}

1) Estimasi pendapatan pada umur tanaman sekitar 5-15 tahun berdasarkan harga apda 13 September 2018. Asumsi Perhitungan Pendapatan petani sebagai berikut :

a) Karet perkiraan produksi Tapanuli Selatan $538 \mathrm{~kg}$ KKK/th atau 44,8 kg/bulan harga Rp12000/kg KKK dihitung dari harga Rp7000/kg slab/lump dengan 60\% KKK.

b) Kopi : perkiraan produksi $600 \mathrm{~kg} / \mathrm{ha} / \mathrm{th}$ atau $50 \mathrm{~kg} / \mathrm{bulan}$ dan harga Rp85.000/kg green bean

c) Kakao : perkiraan produksi 1414,41 kg/ha/th Kecamatan Sipirok atau $118 \mathrm{~kg} / \mathrm{ha} /$ th (sumber : Statistik Perkebunan Sumur 2017 dan harga Rp30000/kg kadar air 12-14\%.

2) Kriteria berdasarkan pengamatan akan kebutuhan pemeliharaan tanaman (pemupukan, pengendalian hama dan penyakit), proses buah sebelum jual, panen dan kemudahan penjualan.

3) Kriteria ini didasarkan wawancara dengan petani oleh.

4) Kriteria ini didasarkan pada penilaian peneliti untuk petani semi intensif (moderate).

5) Kriteria penilaian peneliti :

${ }^{*}=$ sangat mudah; ${ }^{* *}=$ mudah; ${ }^{* * *}=$ sulit daripada karet; ${ }^{* * *}=$ kakao lebih sulit daripada kopi.

$\square$ = tidak suka; $\square \square$ = kurang suka; $\square \square \square$ = suka; $\square \square \square \square$ = sangat suka

$\mathrm{O}=$ kurang baik karena setelah umur TM sulit untuk mix farming; $\mathrm{OO}=$ baik seperti tanam perdu dengan pohon pelindung; $\mathrm{OOO}$ = lebih baik selain kanopinya rapat karena menyerupai hutan (agroforestri).

Masalahnya secara ekonomi karet sangat tidak menguntungkan terutama dalam beberapa tahun terakhir harga karet sangat rendah. Jalan keluarnya adalah memperbaiki sistem sadap karet yang diyakini dapat meningkatkan produktivitas lateks dan memperbaiki sistem tataniaga karet. Kedua program tersebut merupakan usaha agar petani karet tidak melakukan konversi karet dengan tanaman sawit. Oleh sebab itu penyuluhan perkebunan adalah kunci untuk suksesnya sustainable production.

\section{SIMPULAN}

Pada tingkat kelembagaan aspek keberlanjutan dalam proses pembangunan belum terintegrasi dengan baik, walaupun kegiatankegiatan pembangunan sawit berkelanjutan sudah dilaksanakan secara parsial. Peran Kelembagaan yang ada di Tapanuli Selatan yang terkait dengan konservasi SDA belum memadai, karena belum fokus kepada sawit berkelanjutan, masih sangat terbatas pemahaman terhadap perlunya 
kerjasama antar instansi untuk mengatasi masalah petani sawit independen yang ekspansif, karena tidak memahami sistem budidaya sawit yang lebih maju dan konservatif. Mengingat luasnya areal sawit yang perlu ditingkatkan produktivitasnya ditambah dengan kondisi kemiskinan di pedesaan, maka tidak memungkinkan petani melakukan intensifikasi tanpa bantuan. Bantuan pengadaan sarana produksi seperti bibit unggul sawit, pupuk, obatobatan dan peralatan bisa dilakukan misalnya dengan memberi subsidi harga. Model skema pembangunan sawit dispersal perlu dikembangkan bila RADSB skala kabupaten ingin dikembangkan.

\section{DAFTAR PUSTAKA}

Barlow, C. (2001). 'The Role of Institutions in Planting Improved Smallholder Rubbler', in Robert Yapo Assamoi, Kees Burger, Dominique Nicolas, Francois Ruf and Patrice de Vernou (2002) (eds), The Future of Perennial Crops. Investment and Sustainability in the Humid Tropics, Montpellier : Centre de Cooperation Internationale en Recherche Agronomique pour le Developpement and BNETD.

Barlow, C. , Zahari Zen and Ria Gondowarsito (2003), "The Indonesian Oil Palm Industry" Oil Palm Industry Economic Journal Vol 3. No.1

Barlow, C. Zahari Zen and Ria Gondowarsito (2005), Estates and Smallholdings in Indonesian Palm Oil Production : Performance and Prospects, Canberra : Internasional Oil Palm Study Group.
CI-Indonesia (2015) Pendekatan Bentang alam berkelanjutan, Leaflet, Jakarta.

Mangga Barani, A. 2014. Kelapa sawit berkelanjutan di Indonesia, presentation material "Associate Committee Sustainable Palm Oil Program SLP 20 March 2014. Forum Pengembangan Perkebunan Strategis Berkelnjutan (FP2SB).

McCarthy, JF. and Z Zen. (2010) Regulating the Oil Palm Boom: Assessing the Effectiveness of Environmental Governance Approaches to Agro-industrial Pollution in Indonesia Law \& Policy 32(1) p 153-179

Obidzinski, K. Andriani, R., Komarudin, H., and Andrianto, A. 2012. Environmental and social impacts of oil palm plantations and their implications for biofuel production in Indonesia, Ecology and Societ 17 (1):25.Http://dx.doi.org/10.5751/E S-04775-170125.

Palm Oil Agribusiness Strategic Policy Institute (PASPI) 2014. The sustainability of Indonesian palm oil industry its role in Economic Growth, Rural Development, Poverty Reduction, and Environmental Sustainability, Development Economics, Bogor Agriculture University. First Edition.

Zen, Z., Afif S, and Ratna Permata Sari (2018). Positive and Negative Impacts of oil Palm Expansion in Indonesia : A pathway sustaining remnant forest and peatlands, Lambert Academic Publishing, 95p. 
Zen, Z, C. Barlow and R. Gondowarsito. (2006). "Oil Pam in Indonesian Socio - Economic Improvement: A Review of Options", Industry Economic Journal, Vol. 6, pgs 18 to 29
Zen, Z. dan Shahputra, A. (2019). Kajian ekonomi, ekologi dan sosial kelapa sawit di tapanuli selatan, Laporan Final CI-Indonesia. 